\title{
CONTEXTO SOCIAL E IMAGINÁRIO ORGANIZACIONAL MODERNO
}

Professora do Departamento de Administração e Recursos Humanos da EAESP/FGV, Pesquisadora Visitante na Universidade de Paris VII e Autora do livro Cultura organizacional: formação, tipologias e impactos.

E-mail: mfreitas@fgvsp.br

RESUMO

Este artigo analisa algumas das mudanças que vêm ocorrendo no ambiente socioorganizacional e as respostas que as grandes empresas têm dado a elas, especialmente desenvolvendo um imaginário próprio que busca a sua legitimação como ator social central.

\section{ABSTRACT}

This article analyzes some changes happened in the social-organizational environment and the answers given them by big businesses, mainly ones related to a specific imaginary created in order to legitimate them as a central social actor.

PALAVRAS-CHAVE

Ambiente organizacional, cultura organizacional, imaginário organizacional.

KEY WORDS

Organizational environment, organizational culture, organizational imaginary. 
Traindo? Confiança? Sois todos iguais, vós, os realistas: quando não sabeis o que dizer, apelais para a linguagem dos idealistas.

Jean-Paul Sartre - O diabo e o bom deus

Não podemos pensar em organizações independentes do contexto e da época em que se inserem. Isso significa que as organizações devem ser compreendidas dentro de um espaço social e de uma época específicos, constituindo-se, assim, num formato sócio-histórico. O histórico e o social são intrinsecamente ligados, pois não existem relações sociais entre os indivíduos e os grupos nem entre estes e os objetos sociais que se dêem sem referência a um tempo e a um espaço. Toda significação só pode, então, ser compreendida numa prática e num pensamento da sociedade e da História.

Uma sociedade institui-se criando para si a representação de uma visão de mundo, do seu mundo e do mundo que ela conhece. A essa autoimagem liga-se um "querer-se" e um "amar-se" como aquela sociedade, e não como uma outra qualquer. As sociedades e os povos diferem em função do que amam, detestam, querem, desejam, sonham, buscam. Sua auto-representação é fruto do seu passado mas também do seu presente e do seu "querer-se" como um futuro (Castoríadis, 1995). Tudo o que existe numa sociedade é produção dessa sociedade e somente assim pode ser ela compreendida.

Parece corrente o pensamento que atribui às sociedades tradicionais maior riqueza na produção e manifestação do imaginário e do simbólico. As sociedades modernas aparecem como se fossem, se não destituídas desses elementos, pelo menos expressando-os de forma pouco saliente. Ora, uma das características mais marcantes das sociedades modernas é a ênfase na racionalidade extrema ou, ainda, o pós-moderno inaugura-se na "morte de Deus", na perda dos fundamentos, da transcendência, ou seja, no esfacelamento da religião, da ética, da moral e do sagrado. Desenvolveremos um raciocínio inverso: essa racionalidade definidora dos tempos modernos é, ela mesma, repleta de um imaginário e de um simbolismo que não encontram referências em nenhuma outra sociedade, e o imaginário das organizações modernas busca responder à problemática atual de fragilidade no processo de identificação dos indivíduos.

\section{O CONTEXTO SOCIAL DAS ORGANIZAÇÕES MODERNAS}

De todas as imagens que nos vêm à mente quando falamos no ambiente atual, uma se apresenta de forma predominante como causa e conseqüência de tudo o mais: mudanças aceleradas constantes. Vivemos uma torrente de mudanças nos vários campos do social e do humano sem nenhum precedente na História. A palavra que define o momento é "complexidade". Em boa medida, essas mudanças são decorrentes do rápido desenvolvimento econômico das últimas décadas,
É possível identificar o aparecimento do que Freud já chamava de "narcisismo das pequenas diferenças", ou seja, um
individualismo de grupos ou de "tribos". em especial no mundo ocidental, porém elas trazem na sua rasteira uma espiral de efeitos múltiplos e influenciações recíprocas, ainda difíceis de serem apreendidos de uma forma mais precisa. Essa dificuldade comporta algumas explicações, entre elas o fato de não podermos isolar as variáveis independentes das demais, ou seja, o cultural, o econômico, o social, o político, o religioso, o tecnológico estão tão imbricados que alterações em um deles podem significar mudanças simultâneas, e em cadeia, em todos os demais. Aliado a isso há o fato de estarmos dentro do próprio movimento, o que não nos permite um distanciamento necessário para uma compreensão mais abrangente. É sempre possível, porém, pinçar e buscar aprofundar alguns pontos.

A queda das barreiras geográficas traz consigo a consolidação - ao mesmo tempo em que se reforça por ela - de alguns valores mundiais; a elevação mundial do nível de educação contribui sensivelmente para a geração de acréscimos significativos no universo das ciências, impulsionando uma renovação tecnológica incessante; a velocidade na produção e na transmissão de informações faz desaparecer a diferença entre transportes e comunicações; o estoque mundial de capital privado, que vem sendo utilizado para a compra de parcelas do setor público e para o financiamento da pesquisa aplicada, faz com que as empresas tenham um poder decisório - não apenas econômico mas também político - que antes se encontrava nas mãos dos governos.

Por outro lado, a tendência para a rápida destruição dos padrões culturais tradicionais, integrados anteriormente, inclui vários aspectos, entre eles: a re- 
dução do significado da religião e da moral determinada pela religião; a significância reduzida dos papéis sexuais, mudando as atitudes em relação a autoridade, figuras parentais, moral sexual e atributos específicos de classes; e o declínio da ética do trabalho e a instituição de uma forma de vida consumista e hedonista. Percebemos, assim, uma grande fragmentação de valores e condutas pessoais e coletivas, em que a integração social começa a aparecer como problemática.

seja, ele não pertence mais a um lugar específico, ele não está mais preso a raízes familiares, muito menos de vizinhança.

No social mais amplo, verificam-se ganhos enormes em relação às possibilidades materiais de vida, de conforto e de saúde, uma elevação no nível e no acesso à informação, a elevação dos índices de longevidade, uma maior reivindicação de espaços políticos para a representação de novos grupos sociais, bem como o surgimento de novos grupos de negociação. Mas nem tudo são flores no reino do social. O homem, como o grande construtor de todo o social, é também por ele construído, o que significa que a linguagem que fala é a mesma que esconde, que a sociedade que protege é a mesma que mata, que os critérios que incluem são os mesmos que excluem. Queremos dizer que as mudanças ocorridas no social também têm apresentado efeitos colaterais danosos, tais como: desemprego, povos e grupos excluídos de qualquer benefício gerado pelo progresso, maior concentração mundial de renda, estresse em todas as faixas de idade, fuga por meio de suicídios e drogas, poluição, catástrofes am-

Um cenário como esse não pode deixar de apresentar impactos - diretos e indiretos - nos níveis do individual, do familiar, do organizacional e do social mais amplo. Podemos notar, sem dificuldades, que, nas famílias, várias mudanças têm deixado as suas marcas com grande visibilidade: na redução do seu tamanho, na alteração do conceito de família nuclear, na desagregação provocada por divórcios e separações mais freqüentes e fáceis, na convivência de diferentes arranjos de relacionamento, na criação de filhos por terceiros/instituições, iniciando precocemente uma socialização secundária, no surgimento de uma quarta idade e na redução das diferenças entre os valores "geracionais", dando origem ao que Anatrella (1988) chama de uma "sociedade adolescentrique".

Visto isoladamente, o indivíduo não parece mais "feliz" que a sua própria família. A ele se atribui um maior individualismo, dentro de redes sociais cada vez mais virtuais, nas quais ele desenvolve contatos múltiplos com um número cada vez maior de estranhos íntimos; uma maior insegurança, oriunda da falta de referências claras; uma busca de sentido para a vida, sentido esse que se encontra diluído num sentimento difuso de perda; o estabelecimento de um contrato de convivência pacífica com a solidão, às vezes, envolta no manto da privacidade; a perda de laços afetivos primários, o que o predispõe a estabelecer contatos cada vez mais frouxos e "independentes" e o torna mais receptivo a processos de desterritorialização, ou bientais e tantos outros males, só para falarmos dos mais evidentes. Também são claras as referências à fragmentação, fragilização e crise identitária, que cientistas políticos, sociólogos, antropólogos, psicanalistas e outros especialistas tentam compreender.

Várias têm sido as tentativas de se precisar melhor se o que ocorre no momento é apenas um mal-estar no processo de identificação ou algo mais acentuado e que poderia ser chamado de crise de identidade ${ }^{1}$. Têm sido discutidas teses sobre: o enfraquecimento dos vínculos sociais e do universo simbólico, a fragilização das bases identitárias (Palmadade, 1990), a perda de função dos rituais, especialmente aqueles relacionados às práticas religiosas, que lidam com as mudanças e mediam a relação com o divino, mas também os de passagem, nos quais verificamos uma espécie de indiferenciação de comportamentos, não mais associados a idades ou a gerações (Maisonneuve, 1990). ${ }^{2}$ É possível identificar o aparecimento do que Freud já chamava de "narcisismo das pequenas diferenças", ou seja, um individualismo de grupos ou de "tribos". ${ }^{3}$ Há, ainda, o argumento sobre a ênfase nociva que a sociedade atual mantém com a primazia do econômico e a influência da crise nas instituições tradicionais: Igreja, partidos políticos, sindicatos, Estado, escola, etc. (Roustang, 1990).

Para Castoríadis (1990) existe não apenas um malestar, mas uma bela crise da sociedade como um todo, que tem sua origem não apenas numa crise de valores 
mas também nas significações imaginárias sociais. Estas não estariam mais cumprindo as suas funções e, socialmente falando, não existem mais respostas para o sentido do "imortal". O que percebemos é uma sociedade dominada pelo racional e pelos lobbies, o modelo do que ganha mais sem nenhuma relação efetiva entre o trabalho e a remuneração (Madonna, Prince, Trump, etc.), não existindo mais nada nessa sociedade que justifique os valores da integridade, da seriedade. Se esses valores ainda estão presentes é em função de heranças passadas, pois a sociedade tal como se apresenta não justifica a sua existência. Não se ganha pelo que se vale, mas se vale pelo que se ganha. Contrariamente à tese do individualismo, Castoríadis (1990, p.131) crê que a característica predominante da sociedade atual não é o individualismo, mas o conformismo generalizado. "Conformisme qui n'est possible qu'à condition qu'il n'y ait pas de noyau d'identité important et solide." Outros autores têm acusado a mass media pela promoção de pseudo-eventos, espetáculos (Debord, 1967) ou simulacros, em que a aparência é tudo, o falso vale mais que o verdadeiro e a reprodução de tudo é possível (Baudrillard, 1981). Nesse movimento, até a morte é negada ou driblada, e a tecnologia, que pode fazer milagres, pode também trazer do túmulo os grandes ídolos sempre que sua presença for considerada como um bom negócio ou oferecer a oportunidade de um belo espetáculo, como bem demonstra a recente "ressurreição" de John Lennon.

Sabemos que as organizações, especialmente as grandes empresas privadas, apresentam uma maior facilidade em captar as mudanças sociais e responder mais rapidamente a elas que as demais instituições. Elas respondem não apenas de maneira operacional mas também de forma simbólica, via cultura organizacional e repasse de todo um imaginário. As organizações lêem o que se passa no seu ambiente e reelaboram respostas que possam ser direcionadas para os seus objetivos. As organizações são espaços de comportamentos controlados e todo o controle do social passa, necessariamente, pelo controle da identidade. Se existe, neste momento, uma crise ou um mal-estar no processo de identificação dos indivíduos e se a integração social começa a se apresentar como problemática, é necessário desenvolver mecanismos capazes de dar respostas a essas questões e realinhar o processo de adaptação ao novo cenário mutável, redistribuindo a importância dos papéis dos atores sociais.

Nessa redistribuição, as organizações modernas assumem uma importância que nunca tiveram antes e se oferecem o papel de ator central ${ }^{4}$ da sociedade, por meio do qual todas as demais relações devem se organizar. Elas pretendem ser o modelo de racionalidade, de transparência, de produtividade e de resultado que as demais instituições presentes no corpo social devem seguir. A relação com o trabalho ou com o lugar do trabalho tende a se tornar a principal referência dos indivíduos ou, de outra forma, as organizações modernas no contexto citado - assumem voluntariamente o papel
As organizações, especialmente

as grandes empresas privadas, apresentam uma maior facilidade em captar as mudanças sociais e responder mais rapidamente a elas que as demais instituições. de fornecedores de identidades tanto social quanto individual, contaminando o espaço do privado e buscando estabelecer com o indivíduo uma relação de referência total. Essa tentativa vai se dar por meio da produção de um imaginário específico, no qual a organização aparece como grande, potente, nobre, perfeita, procurando captar os anseios narcisistas de seus membros e prometendo-lhes ser a fonte de reconhecimento, de amor, de identidade, podendo preenchê-los e curálos de suas imperfeições e fragilidades. ${ }^{5}$

\section{O IMAGINÁRIO ORGANIZACIONAL MODERNO}

Até recentemente, as grandes empresas (big businesses), especialmente as multinacionais, precisavam ser bastante cuidadosas e privilegiavam uma imagem discreta, a fim de evitar serem acusadas de fazer uso do poderio econômico para exercer influência política nas sociedades nas quais elas se instalavam. Esse comportamento discreto e cauteloso lhes permitia fundar sua legitimação numa base de competência e de compatibilidade com o projeto de desenvolvimento da região ou do país onde elas se situavam, o que lhes garantia uma aparente neutralidade. Mesmo assim, as palavras "big business" e "multinacional" traduziam uma má reputação. ${ }^{6}$ Elas eram acusadas de provocar desemprego, de sonegar impostos, de influir politica- 
mente nos governos dos países em que se instalavam, de concorrer deslealmente, de causar danos ecológicos, de, enfim, ser imorais. Não se passou ainda uma década e temos, hoje, um panorama completamente diferente.

Podemos perceber atualmente, não apenas nas sociedades ocidentais, um movimento de revalorização ${ }^{7}$ do papel das empresas. Esse movimento se deve, em grande medida, à "confirmação" do capitalismo como a "única" via capaz de promover o desenvolvimento econômico e a crescente legitimação da ideologia neoliberal, em que o econômico assume o papel predominante e subordina todas as demais esferas da vida social. A crise nas instituições tradicionais da sociedade fomenta essa primazia do econômico. É verdade que toda a sociedade deve ser capaz de desenvolver as condições de sua sobrevivência material, mas é neste momento histórico específico que podemos verificar uma tendência reducionista que atribui ao aspecto econômico a importância de todas as coisas. A própria política se transforma numa simples gestora de índices econômicos.

Além desses fatores - sem dúvida nenhuma importantes -, é também a crise de identidade vivida pelos indivíduos nessa sociedade ocidental que permite a ampliação do papel das organizações modernas. Quanto mais as referências culturais e religiosas, tradicionais, se quebram, mais os indivíduos e grupos se mostram receptivos a acatar mensagens e líderes que lhes possam oferecer uma resposta que traduza um pouco mais de certeza e lhes permita o reconhecimento de um caminho, de um sentido para a vida. Numa sociedade em que é exaltada a importância da imagem, da aparência, do consumo, da superficialidade, as organizações modernas encontram um terreno fértil para se posicionar como o grande referente que propõe uma forma de vida de sucesso e uma missão nobre a realizar. O Estado falido e desacreditado - deve se restringir a oferecer as condições necessárias de infra-estrutura e deixar que as empresas se ocupem do que garante o emprego, a competitividade dos mercados e a potência da nação neste mundo globalizado.

Investidas como o novo pólo da legitimação social e como o lugar que pode responder pelo esfacelamento dos vínculos sociais e pelas questões identitárias, as organizações modernas - com ênfase nas grandes empresas - constroem para e de si uma auto-imagem grandiosa, que vai enraizar-se num imaginário próprio, que é repassado não apenas para os seus membros internos mas também para a sociedade no seu conjunto. Vejamos, mais de perto, alguns dos temas que são hoje privilegiados por esse imaginário e como ele encobre as funções que são preenchidas.

\section{A empresa-cidadã}

É lícito reconhecer a importância que as empresas têm exercido no desenvolvimento econômico das sociedades atuais, mas essa relevante função não altera a sua finalidade básica: a de produzir - com lucro - bens e serviços destinados a um mercado. A crise econômica contribui para reforçar o seu papel, porém não é suficiente para modificar a sua essência.

O conceito de cidadania é de uma outra natureza e implica, necessariamente, a superação de interesses particulares, a consciência do bem comum, a noção de igualdade e liberdade, de respeito pelos direitos do outro, bem como o reconhecimento da necessidade da presença de diferentes atores no debate político sobre os negócios da cidade e da nação por inteiro. O político e o social se fundem e se sustentam numa representação, num desejo, num projeto e numa vivência de coletividade capaz de identificar-se como pertencendo àquela, e não a outra sociedade, ou seja, a cidadania é um estatuto entre uma pessoa natural e uma sociedade política, portanto privativo do indivíduo e dos seus direitos/deveres civis. Um sistema artificial como uma empresa, uma associação, pode ter uma nacionalidade, mas certamente não uma cidadania.

As empresas falam em seus nomes e em nome de seus interesses, dos quais não perder é um dos mais fortes. Falam em nome das categorias e dos setores econômicos que representam, defendendo, portanto, interesses parciais e legítimos. Pretendem, contudo, falar em nome de todos e se apresentam como isentas de críticas ou envoltas num manto de bommocismo. Sabemos que, quando o econômico é o critério decisivo, as empresas podem fazer coisas bem absurdas do ponto de vista do cidadão: safras inteiras podem ser queimadas para elevar o preço do seu produto, independentemente da fome à sua volta; aplica-se no mercado financeiro e reduz-se a atividade produtiva e empregadora; muda-se para um outro país onde a estrutura de custos seja mais barata, não importando a massa desempregada que elas deixam atrás de si; apóiam campanhas de todos os candidatos em uma mesma eleição para garantir a "simpatia" futura; incentivam guerras dos dois lados para vender mais armas; podem, desde que seja possível, substituir por máquinas todas as pessoas que nelas trabalham, não apenas porque as máquinas são mais velozes e "erram" menos, mas por todas as implicações da presença do trabalhador; fazem lobbies pesados para defender a aprovação de alguns projetos que lhes garantam alguns privilégios específicos, em detrimento do preço a ser pago por todos os demais. Enfim, a "consciência" das empresas limita-se ao que lhes garante que perma- 
neçam no jogo e que o ganhem. Estarão elas erradas? Não, ganhar o jogo é a sua missão e a sua natureza ou, como já dizia Guerreiro Ramos, "não se pode culpar o leão por ser carnívoro".

No discurso de cidadania das grandes empresas, duas frentes têm sido privilegiadas: apoio à cultura e à ecologia. No caso de apoio a projetos culturais, nunca se menciona o retorno que tais projetos podem proporcionar, seja em imagem institucional, seja em dividendos políticos, seja em redução de custos de campanhas publicitárias. Ora, cada vez mais a publicidade convencional apresenta limites de eficácia; atualmente, busca-se uma valorização da empresa como um todo, e não de um produto específico. Cada vez mais os produtos são efêmeros, mas uma marca consolidada é sempre uma marca garantida, não importando que produto ela decide vestir. A indústria cultural é um verdadeiro setor econômico, e as ações empresariais não devem ser confundidas com caridade, altruísmo ou mecenato. Mais uma vez, não estamos dizendo que as empresas estão erradas em enveredar por esse caminho, mas estamos, sim, marcando o que se trata de um discurso que procura, conscientemente, induzir ao equívoco.

A questão ecológica levanta entusiasmos e enganos semelhantes. Por um lado, não é favor a nenhum país preservar o que pertence ao planeta de todos. Por outro, cada vez mais é verdade que, para se exportar para alguns mercados, é necessário obedecer a alguns critérios que consideram a redução de danos ecológicos, como a utilização de matérias-primas não-tóxicas e que não estejam em risco de extinção, a produção de embalagens que sejam recicláveis, a não-utilização de seres humanos como cobaias, a preservação da flora e da fauna dos ecossistemas ameaçados, o fato de não comprar a miséria de crianças e do trabalho escravo, etc. Não é uma questão de agradar ao Greenpeace ou a outros organismos internacionais de vigilância, mas é evitar ficar com produtos encalhados, com uma imagem internacional manchada e correr riscos de ser alvo de boicotes e sabotagens. A discussão ecológica era, até pouco tempo atrás, considerada um passatempo de meia dúzia de hippies que voltaram a pé do Woodstock I, mas a causa saiu do diletantismo. Constituiu-se em bandeira política de partidos políticos específicos, estando presente, de uma forma ou de outra, no mundo das intenções de todos. O risco aqui é o de transformar-se em vilão ou em inimigo da humanidade, ou seja, muito grande para ser enfrentado. Respeitar a ecologia, se não dá dinheiro, pode evitar muito prejuízo.

\section{O lugar da excelência}

A palavra "excelência"8 mudou, recentemente, de significado. Agora não se trata mais de um valor durável, um atributo ou uma qualidade superior. O que antes era um infinitivo - ser excelente - passou a ser um gerúndio - sendo excelente. Ela adquiriu mobilidade, transformou-se num patamar, numa seqüência sempre ascendente de posições, num quebra-recordes, numa corrida de ultrapassagem. Essa escala móvel define hoje os paraísos e os infernos temporários das empresas e de todos os que nelas estão.
É também a crise de identidade vivida pelos indivíduos nessa sociedade ocidental que permite a ampliação do papel das organizações modernas.
Uma espécie de esquizofrenia coletiva toma conta de todos - em especial dos altos escalões -, já que o risco de ser superado, no menor espaço de tempo possível, está sempre à porta. Os conteúdos devem ser sempre atualizados, os indivíduos e os grupos devem buscar sempre doses maiores, os saberes se tornam imprestáveis com extraordinária velocidade, os heróis de hoje não servem como referência para amanhã, os valores atuais já estão obsoletos. A excelência tornase a palavra-chave e a condição maldita de sobrevivência de pessoas e empresas. Torna-se um valor em si mesma e nada é mais superável que o Guinness Book, que só existe para citar a referência que não serve mais.

Perseguir a excelência mutável não é apenas obrigação, mas a sina de todos. As empresas tornam-se o lugar em que essa sina deve ser vivida e vão cobrar, rigorosamente, de cada indivíduo que não apenas seja, mas que queira ser esse herói incansável. Elas lhe dizem para se considerar o "empreendedor de sua própria vida", que ele seja o "seu próprio projeto", que ele se veja como um "capital que deve dar retorno". A excelência, como um patamar deslocável cada vez mais para o alto, é o único lugar que esse indivíduo pode almejar, é o único lugar que lhe permite realizar-se, é o único lugar no qual ele pode existir. O seu "ideal de ego" estará sempre sedento e faminto, colocado a provas constantes e incapaz de se satisfazer (Aubert e De Gaulejac, 1992).

Ora, a excelência se desloca do "ser" para o "fazer", e são as organizações os espaços em que esses resultados devem ser atingidos. O padrão, sempre crescente, 
será a exigência-chave não apenas para a qualidade do trabalho, mas se constituirá num sistema moral que engloba toda a conduta do indivíduo. A carreira, ou o status profissional, torna-se o elemento organizador da vida pessoal, aquilo que lhe dá sentido, auto-imagem, reconhecimento e o único referente que lhe pode permitir a expressão do sucesso e da realização pessoal. A identidade profissional torna-se a identidade pessoal. Mas essa identidade está sempre em xeque, uma vez que ela só se admite como o sucesso excelente. Mas esse excelente tem gradações, e o padrão de ontem já foi conquistado; se o indivíduo não é diariamente esse herói quebrador de recordes, ele é um joãoninguém, um morto-vivo, sem identidade, sem autoimagem, sem reconhecimento.

As organizações modernas sustentam a possibilidade de todos serem heróis, desde que todos assumam a sua "natureza" esportiva de ganhador. O heroísmo é socialmente transmissível", a ação é supervalorizada quanto mais rápido é o tempo em que tudo deve se dar. O Narciso que existe em cada um é chamado a se manifestar, não de vez em quando, mas a assumir o seu lugar de direito permanente. A desmedida, como sendo a ultrapassagem do parâmetro, é a medida de todos. Essa excelência, contrariamente ao que tem sido alardeado como algo que só comporta um lado positivo, pode mascarar uma perversidade e uma força mortífera não apenas para os indivíduos, mas para as próprias organizações, bastando imaginar o que vem ocorrendo nos bastidores de preparação dos atletas olímpicos. Quando superar é só o que importa, os anabolizantes simbólicos não fazem a menor diferença, pelo menos não no curto prazo que garante a medalha. Extrapolese isso para a arena competitiva das empresas!

\section{O lugar da juventude eterna}

As organizações modernas parecem ter conseguido não apenas romper as barreiras do espaço geográfico, multiplicando-se em um mercado sem limites, mas também ter derrubado as barreiras do tempo. Ainda que a evolução tecnológica tenha nisso um grande papel e suporte, é a mentalidade que fornece o núcleo e o motor da ação renovada sempre, num tempo que só existe como relações múltiplas no presente.

Ainda é verdade que, para o homem ocidental, ficar mais velho é aproximar-se mais da morte que da sabedoria. As empresas, porém, capitalizam a idade de uma outra forma. Ela é sinal de dinamismo, de sucesso, de potência, de reversão das dificuldades a seu favor, de poder mergulhar na fonte da juventude, fazendo as cirurgias plásticas necessárias - via incorporação de novas técnicas, novos processos e novas práticas. É quase como se as empresas tivessem descoberto a fórmula da imortalidade. É preciso negar a morte, é preciso ser jovem sempre. É a necessidade transformada em qualidade, em virtude, criando exigências cada vez mais acentuadas de agilidade, rapidez e força.

A palavra "flexibilidade" cai do céu como uma luva ou uma benção. Ela é tudo o que há de mais caro atualmente às organizações, pois representa o que garante esse rejuvenescimento permanente, que dá o tom do que é moderno, vivo e válido. Ela é a varinha mágica que renova estruturas, saberes, comportamentos, condutas, métodos, pensamentos, visão de mundo, representações, conceitos.

O ser flexível tornou-se o sonho dourado de todas as empresas, e conseguir ser flexível, a necessidade desesperada, o pesadelo dos executivos atuais, por ser condição de sobrevivência. Ser flexível e excelente é o "único" preço que os indivíduos têm de pagar para chegar e manter-se no pódio. Todos estão convictos da necessidade de chegar ao pódio, mas também sabem que não existe pódio para todos. Há, em cada organização e em cada indivíduo, um ponto de exaustão cada vez mais próximo de ser atingido. É a eterna ameaça da guilhotina!

A maneira de driblar essa necessidade de renovação constante é colocando a organização como o lugar do desenvolvimento pessoal e o único em que a sua realização pode se dar. Com um objetivo como esse, a renovação de energias será sempre de forma garantida. É preciso mobilizar o sujeito de forma total. Ser flexível não é mais condição de sobrevivência no trabalho, mas condição de vida. Nessa luta alucinada, as organizações investem em qualquer método, receita, guru, treinamento ou prática que lhes possa assegurar uma promessa de tornar flexíveis os seus quadros. Semanas na selva, guerrilhas, cristais, florais, astrologia, numerologia, neurolingüística, filosofia, zen-budismo, artes marciais, uma infinidade de práticas e pregações tem sido tentada para rapidamente tornar todos superadaptáveis. A racionalidade exaltada, nessa hora, cede lugar à uma irracionalidade quase insana.

Um pouco de cautela não faz mal a ninguém, e sabemos bem que todo excesso é prejudicial, sendo alguns letais. Ora, parece razoável supor que, transformando a flexibilidade num valor em si mesmo, as organizações correm o risco de cair na própria armadilha. Flexibilidade, quando excessiva, não constrói nada, não consolida nada, não gera nada durável, não referencia nada, não garante nem a própria sobrevivência, já que não armazena nenhuma memória capaz de orientar uma tomada de decisão imprevista. A literatura e a dramaturgia mostram-nos que, por trás de cada fonte da imortalidade, há sempre uma alma penada... Mas as organizações não têm alma, ou têm? 


\section{A empresa como restauradora da ética e da moralidade}

Não é novidade alguma o fato de as organizações terem, seguidamente, se utilizado de discursos nos quais o homem aparece como o centro de suas preocupações. Evidentemente, sempre existiu um grande abismo entre o mundo das intenções e a realidade cotidiana.

Mais uma vez lembramos que as organizações são produto e produtor dos ambientes em que atuam. A competitividade atual não apareceu do nada e são as próprias empresas que dela participam que estabelecem as regras. Quando o ambiente começa a se tornar nocivo ao próprio jogo, é preciso modificar o ambiente para que o jogo possa continuar.

$\mathrm{O}$ modelo que consagra aquele que ganha de qualquer jeito tende a esgotar-se na própria produção exclusiva de um mundo de cínicos, delatores, sabotadores, espiões, traidores, quebradores de contratos, corruptos, etc. Um lamaçal desse tipo não pode produzir frutos nem gerar o mínimo da confiança necessária para que as organizações possam desenvolver suas atividades por um tempo maior que o curto prazo. É necessário, pois, dar um basta e limpar as relações organizacionais. Não existem anjos nem inocentes nesse jogo, mas existem conveniências e a necessidade de um mínimo de credibilidade para que as organizações possam operar, gerar lucros, crescer e expandir. Todos os dirigentes sabem que um ambiente habitado exclusivamente por cínicos apenas ressalta as fragilidades organizacionais e, de resto, apodrece o tecido social como um todo.

O movimento pela ressurreição da ética leva a supor que o ambiente estava se tornando mortífero e que as condições mínimas de confiabilidade estavam perecendo. A imprensa mundial deu mostras de ser extremamente eficaz e assumiu ares de corajosa e independente ao fazer inúmeras denúncias de corrupção, negociatas, espionagem industrial, quebra de sigilo de governos e empresas, exploração de trabalho escravo, etc. Vários dirigentes organizacionais, políticos, estadistas de um bom número de países sabem que têm uma parcela de culpa pelo lamaçal que estava se espalhando pelo planeta. É sempre bem-vinda qualquer atitude que busque corrigir esse caminho que leva ao suicídio moral coletivo.

As organizações modernas apresentam-se agora não apenas como o modelo de gestão eficaz que deve ser seguido pelas demais instituições da sociedade, mas também como as guardiãs dos valores sociais mais elevados e da moralidade pública. Guardiãs da Honestidade, do Respeito, da Seriedade, da Transparên- cia, da Dignidade, responsáveis por uma missão nobre, elas se pretendem ares de santidade. A megalomania parece ser o pecado mais freqüente das organizações, que não se satisfazem em apenas corrigir erros, mas tentam apagar o passado, impedindo, assim, a aprendizagem que só a crítica e a reflexão podem gerar.

É impressionante a maneira como as organizações modernas buscam transformar a necessidade em virtude. Na mesma linha do que já discutimos sobre a questão ecológica, podemos ver esse movimento pelo retorno de posturas mais éticas; podemos observar no exemplo do banqueiro, cuja confiabilidade,
A excelência torna-se a palavra-chave e a condição maldita de sobrevivência de pessoas e empresas. Perseguir a excelência mutável não é apenas obrigação, mas a sina de todos. que é - ou deveria ser - condição sine qua non, é alardeada como uma qualidade. Ser responsável e cumprir as leis é questão obrigatória; respeitar a dignidade individual, as crianças, os velhos e os animais é requisito de humanidade, independentemente de religião; zelar pelo planeta é, na mais pobre das hipóteses, garantir um espaço de sobrevivência aos seus descendentes.

Não estamos desqualificando o esforço que vem sendo feito pelas organizações para se estabelecerem relações mais decentes, mais confiáveis, mais responsáveis. Pelo contrário, louvamos cada bom exemplo dado. Mas daí a assumir o discurso tal como vem sendo "vendido", como um produto, uma tecnologia de convencimento, é outra coisa. Talvez uma postura mais humilde, de quem reconhece o erro cometido, de quem sabe que não há como continuar sem confiança entre os parceiros, possa produzir um efeito mais profundo e duradouro e, certamente, esse é um ponto de convergência de todos os que fazem e pensam seriamente uma sociedade.

\section{A empresa-comunidade}

As organizações modernas/empresas utilizam-se também do discurso de ser uma comunidade ou uma grande família. A identificação que é solicitada aos 
indivíduos a elas ligados não mais diz respeito apenas às competências profissionais, mas se amplia para as comportamentais e relacionais.

sas captarem as mudanças no meio ambiente e a elas responderem de maneira mais rápida que as demais instituições da sociedade. Podemos supor que as organizações se dão conta do que Anatrella (1988) chamou de "sociedade adolescentrique", ou seja, um novo tipo de sociedade em que os relacionamentos tendem a ser mais horizontais que verticais, mais parecidos com o que define as relações entre tios e sobrinhos ou entre os membros de um mesmo clube, próprias da confraria.

Segundo Anatrella, a adolescência é prolongada e as relações laterais tendem à permanência. $\mathrm{O}$ adolescente torna-se mais "independente" em relação aos pais (e à autoridade) sem realizar completamente seu trabalho de individuação e negando as diferenças de comportamento

Mecanismos diversos têm sido criados para expandir as áreas de influência das empresas sobre os indivíduos. A criação de espaços "soft", de lazer, de recreação e de integração social, como clubes, colônias de férias, academias de ginástica, etc., não traduzem mais nenhuma novidade. O local de trabalho é também o lugar do hobby, do lúdico, do poético, da convivência harmoniosa entre escalões hierárquicos democraticamente embaralhados, cuja pretensa proximidade dilui as diferenças e os conflitos.

Da mesma forma, a casa ou o universo privado de cada um também tende a ser integrado à empresa por meio do computador conectado em rede (pode-se trabalhar um pouquinho mais a qualquer hora sem necessidade de deslocamento ou de tirar o pijama). As definições de férias agora são também passíveis de serem decididas pelas empresas, pelo menos para uma parcela premiada por seus recordes espetaculares. Uma aliança é feita com os próprios familiares dos membros da empresa a fim de incentivá-los a produzir o máximo e a fazer jus aos paraísos gregos ou caribenhos em disputa. Existe ainda espaço para a expressão de sentimentos de religiosidade, ou seja, o psicoespiritual também está sendo zelado, por meio de cursos, palestras e práticas orientais de relaxamento, aumento de concentração e controle de estresse.

A empresa passa a ser o lugar onde o trabalho, a convivência e os laços fraternos se juntam de forma entusiasmada e prazerosa. Uma aventura gostosa a ser compartilhada por todos os colaboradores. Não existe espaço para os indiferentes. Os rituais existem para serem cumpridos e vividos com emoção. Tudo em nome da sociabilidade.

Comentamos anteriormente o fato de as empre- entre as gerações. Os problemas não são mais negociados, porém evitados, e a tarefa educativa dos pais é quase esvaziada. O narcisismo, vivido fortemente na adolescência, em vez de ser promotor de diferenciação e individuação do sujeito, pode levá-lo ao conformismo, ao próprio desaparecimento nas relações grupais. O narcisismo atinge um paradoxo bem singular: ser igual a todo mundo (à imagem de um clã). Nesse quadro, a relação educativa é a da sedução, com uma pseudo-igualdade e pseudoproximidade, privilegiando a camaradagem entre os membros da "tribo". Parece que as organizações modernas captaram esses ventos, ou será uma mera coincidência?

\section{CONCLUSÃO}

Reafirmamos que o contexto social atual, extraordinariamente mutável, não nos permite ainda uma visão clara de todas as implicações para o universo organizacional, porém aponta para diferenças substanciais quanto a uma nova forma de viver não apenas o mundo do trabalho mas o das relações sociais, em geral cada vez mais indiferenciado daquele ou cada vez mais indistinto do que nele ocorre.

Apesar de ser verdade que, na disputa por maiores ganhos de competitividade, as empresas tendem a se abrir em relação aos indivíduos que nelas trabalham, elas parecem, na realidade, estar se fechando, produzindo um imaginário auto-referente, falando só de si, excluindo o outro, numa tradução ampliada das tribos urbanas ou com um forte "narcisismo das pequenas diferenças". Em outras palavras, buscando uma homogeneização que em nada favorece os ganhos que o aprendizado com a diferença garantem, as organi- 
zações, em vez de se tornarem mais capazes de lidar com a complexidade que os desafios atuais colocam, tendem a fazer um gol contra. Nesse caso, em vez de contribuir para amenizar a atual crise de identidade, elas a agravam (e aí Castoríadis toca no ponto sensível do conformismo generalizado).

Um bom ambiente de trabalho é condição necessária para um bom desenvolvimento profissional, mas é só uma parte. O sentimento de identidade social é fortemente ancorado na relação profissional, mas não se esgota nela. Quando as organizações incentivam o estreitamento das relações sociais apenas no seu interior, elas não estão prejudicando apenas os indivíduos, mas a si próprias na medida em que eles tenderão a não reoxigenar seus contatos e a desenvolver, em médio e longo prazos, relações intoxicadas e circulares, ou seja, um crescimento estagnado. É saudável para as pessoas e para as organizações que elas mantenham contatos múltiplos e diversos, que vejam, pensem, sintam, discutam com outros que não aqueles presentes no seu dia-a-dia de trabalho. E isso é tanto mais verdade quanto mais mutável é o ambiente, quanto mais as variáveis se multiplicam, quanto mais a diversidade é a norma.
Em relação à identidade, as organizações não podem fornecer nada mais que referências parciais e contraditórias. O tipo de ser que elas pretendem formar é o retrato das próprias contradições que abrigam no seu seio. Elas dizem ao indivíduo para ser combativo, agressivo, individualista, mas, ao mesmo tempo, ele deve colaborar, integrar-se na equipe e fazer parte do time; pedem que ele seja inovador, criativo, ousado, mas que obedeça à tradição e não provoque rupturas; elas querem que ele tenha iniciativa, mas sendo obediente; ele deve ser orgulhoso de estar no time, mas deve sempre provar que merece o lugar do outro; ele pode tudo, mas não sabe de nada; ele é grande e potente como elas, mas frágil a cada reestruturação que elas farão; querem que ele seja herói numa maratona que não tem fim, fazendo com que ele corra pelo próprio movimento em direção ao alvo, uma vez que este não é para ser atingido. No limite, o que elas pedem é que ele seja diferente sendo o mesmo que os outros, que ele as ame independentemente de ser amado, que confie nelas mesmo que elas dêem mostras de não ter merecimento, que ele almeje sempre o troféu que não existe. De resto, as organizações são, e tendem a continuar sendo, objetos fascinantes e provocativos. $\bigcirc$

REFERÊNCIAS BIBLIOGRÁFICAS

ANATRELLA, Tony. Interminables adolescences: les 12 30 ans. 7. ed. Paris : Cerf/Cujas, 1988.

AUBERT, N., DE GAULEJAC, V. Le coût de l'excellence. Paris : Seuil, 1992.

BAUDRILLARD, Jean. Simulations et simulacres. Paris Galilé, 1981. (Col. Debates).
CASTORÍADIS, Cornelius. La crise du processus identificatoire. Connexions, n. 55, p. 123-35, 1990.

CASTORÍADIS, Cornelius. A instituição imaginária da sociedade. 3. ed. Rio de Janeiro : Paz e Terra, 1995.

DEBORD, Guy. La société du spetacle. Paris : Gallimard, 1967.
MAISONNEUVE, Jean. Crise des rituels et néo-rituels? Connexions, n. 55, p. 29-43, 1990.

PALMADADE, Jaqueline. Postmodernité et fragilité identitaire. Connexions, n. 55, p. 7-28, 1990.

ROUSTANG, Guy. Primat de l'economique en question et devenir social. Connexions, n. 55, p. 101-8, 1990.

\section{NOTAS}

Este artigo baseia-se em pesquisa financiada pelo Núcleo de Pesquisas e Publicações (NPP) da EAESP/FGV intitulada "A questão do imaginário e a fronteira entre a cultura organizacional e a psicanálise".

1. Em seu número 55, a revista Connexions, da editora Érès, lançou, em 1990, um debate sobre o tema "Malestar na identificação", que reuniu especialistas e intelectuais diversos.

2. Podemos identificar, neste artigo, um argumento que vai na mesma direção do exposto por Anatrella, já citado, sobre a "sociedade adolescentrique".

3. 0 termo "tribo" tem sido usado por Michel Maffesoli para dar conta dos vários tipos de grupos que surgem nas sociedades contemporâneas. "Grupalismo" ou "neotribalismo" são também termos utilizados. Ver: 0 tempo das tribos. Rio de Janeiro : Forense, 1987.
4. No sentido analisado por Eugène Enriquez em L'entreprise comme lieu social: un colosse au pied d'argile. In SAINSAULIEU, R. (Dir). L'entreprise: une affaire de société Paris : Fonds National de Science Politique, 1990. p. 203-28.

5. Ver a análise feita por Max Pagès et al. em L'emprise de l'organisation. Paris: PUF, 1979 e também ENRIQUEZ, Eugène. L'organisation en analyse. Paris : PUF, 1992.

6. Ver HALLIDAY, Tereza Lúcia. A retórica das multinacionais. Rio de Janeiro: Summus, 1987. A autora desenvolve um estudo sobre multinacionais no Brasil, Estados Unidos e França, levanta as principais acusações sofridas por elas e a maneira como desenvolvem estratégias de legitimação, que passam, necessariamente, pela utilização da palavra e da criação de imagens que dêem sustentação ao seu discurso.
7. Alguns autores têm se referido a esse movimento como de "reabilitação". Ver, por exemplo: D. Segrestin em tese intitulada "La reabilitation de l'entreprise: un vue sociologique", defendida em 1988, no Instituto de Estudos Políticos de Paris. Outras referências podem ser encontradas em SAINSAULIEU, R. (Dir). L'entreprise: une affaire de société. Paris : Fonds National de Science Politique, 1990. p. 203-28.

8. A revista Autrement, n. 86, de janeiro de 1987, lançou um belo e rico debate sobre o tema "Excelência: um valor pervertido".

9. Ver artigo de Alain Ehrenberg na revista Autrement, n. 86, de janeiro de 1987, e seu livro Le culte de la performance. Paris : Calmann-Lévy, 1991. 